\section{Proteases and biological control}

Proteases and Biological Control. (Cold Spring Harbor Conference on Cell Proliferation, Vol. 2.) Edited by E. Reich, D. B. Rifkin and E. Shaw. Pp. $x+1021$. (Cold Spring Harbor Laboratory: Cold Spring Harbor, New York, 1975.)

THE very many different ways in which proteases contribute to biological control systems is the strongest single impression given by this conference report. Thus, although proteolytic enzymes have been studied for more than three-quarters of a century, it is only recently that it has become apparent how many different control mechanisms depend on these enzymes.

The work of Bayliss and Starling (1902) on the conversion of trypsinogen to trypsin by enterokinase is mentioned as an early example (K. A. Walsh). The first section on structure-function relationships also contains a valuable contribution from $\mathrm{H}$. Neurath on limited proteolysis and zymogen activation. In the report of a meeting devoted to proteases and biological control, it is hardly surprising to find sections on coagulation, complement and kinins, and fibrinolysis. All, however, are excellent and have given the individual contributors the opportunity both to present recent results and to review their special fields.

The more fundamental aspects of protease action are made more comprehensible by a contribution on the specificity of proteinases toward protein substrates (J. S. Fruton). Also contributing towards an understanding of physiological control systems is the section on proteinase inhibitors in which the roles of both $\alpha_{1}$ antitrypsin and $\alpha$ macroglobulin are discussed. A number of rather disparate contributions appear in a section entitled Cellular Aspects of Proteinase Action. In one mainly devoted to protein turnover in animal cells, R. T. Schimke raises some fundamental question-such as the reason why proteins undergo continuous degradation in vivo. As he points out, a partial answer may be the possibility that about $15 \%$ of all proteins contain substitution errors incurred during synthesis. Another important reason for general turnover is also considered, that in its absence, the degradation of particular proteins, needed as part of many physiological changes, would require a set of specific proteinases as numerous as the proteins to be degraded.

A final section on tumour-associated proteinases contains several interesting contributions-for example on plasminogen activators, which are reported to increase in concentration by a factor of 50 after neoplastic transformation of primary fibroblasts.

In view of the wide coverage, excellent quality of the individual contributions and rapid developments occurring in the field, the book deserves a warm welcome.

A. H. Gordon

A. H. Gordon is a member of the scientific staff at the National Institute for Medical Research, London, UK.

\section{Ornament of our times}

Handbook of Psychopharmacology. Section 1: Neuropharmacology. Edited by Leslie L. Iversen, Susan D. Iversen and Solomon B. Snyder. Vol. 1: Biochemical Principles and Techniques in Neuropharmacology Pp. xiii +298. \$27. Vol. 2: Principles of Receptor Research. Pp. xii +288. \$27. Vol. 3: Biochemistry of Biogenic Amines. Pp. xii+486. \$37. Vol. 4: Amino Acid Neurotransmitters. Pp. $x i+317$. $\$ 30$. Vol. 5: Synaptic Modulators. Pp. $\mathrm{xii}+381$. \$35.40. Vol. 6: Biogenic Amine Receptors. Pp. xii +307 . \$30. (Plenum: New York and London, 1975.)

AfTER listening at a Journal Club to a presentation of the latest contribution of Scandinavian psychiatric epidemiology, Sir Aubrey Lewis was once heard to remark that this was not the sort of work which one could criticise, but was an opus magnum simply to be admired. The audience was somewhat astonished, never previously having detected any faltering in their professor's critical appetite. After delivering this one line, however, Sir Aubrey proceeded unabashed in his usual sharp and telling style, and everyone was much re-assured.

This set of six books on basic neuropharmacology represents only the first of three runs which will together comprise the complete Handbook of Psychopharmacology. We are therefore at this point looking at only part of a very large design. But even at this early stage we must unequivocally welcome the production of an ornament of our times. Here is a work which bears witness to the excitement and distinction of a branch of scientific investigation which has burgeoned over recent years. There is nothing in these books which is plodding or pedestrian, and nothing of the anxious pedantry which is sometimes the stuff of the Handbook which is desperately determined to miss nothing. A galaxy of scientists from many countries have contributed. To attempt the usual re- view summary of contents would inevitably mean such condensation as to be misleading. It is sufficient to say that every important basic scientific aspect of this subject is authoritatively dealt with, and the subject explored out to its frontiers.

So much in essence for Sir Aubrey's opening statement. Following his example, it would however, be churlish not to offer some critical comment on an enterprise so eminently worthy of serious scrutiny. The largest problem which the editors had to face was obviously that of how to order and sort all the various issues, so as to produce a work which served the likely purposes of many different readers. There can be no absolutely satisfactory way of meeting such a sorting problem--to confine the coherence of one set of themes to entire chapters, other themes may inevitably be scattered between volumes. As a sort of test run, it was therefore interesting to look up the entries for phenothiazines in the index of each of these six volumes-no doubt the drug will again be treated in a later psychopharmacology section. What transpires is that in Volume 1 there is discussion of immunochemical assay (which certainly stands by itself). In Volume 2 the drug gets a mention in the EEG Chapter (blocking of dopaminergic transmission), and in the discussion of structure-activity relationships. Influence on 5-hydroxytryptamine and bearing on neuropharmacological theories of schizophrenia comes in Volume 3, whereas in Volume 4 the effect of chlorpromadine on brain GABA levels, and glycine and glutamate uptake, is discussed; and again the blockage of dopamine receptors. In Volume 5 , influence of phenothiazines on brain energetics is dealt with (touching again on 5-hydroxytryptamine and dopamine), and later the inhibition of response to norepinephonine. In Volume 6 aspects of the dopamine questions come up once more, and in discussing the structural modification of phenothiazines and related dopamine receptor-blocking, line illustrations have to be produced which hark back to Volume 2 .

There might in the next edition be further room for editorial tidying up. but the design of the enterprise in terms of basic science first and clinical application only later, is probably right and inevitable. It is Sir Aubrey's opening statement which stands.

Griffith Edwards

Griffith Edwards is Reader in Drug Dependence in the University of London, and Honorary Director of the Addiction Research Unit, Institute of Psychiatry, London, UK. 